\title{
IDENTIFICATION OF LEGIONELLA PNEUMOPHILA ANTIGENS AND ANTIBODIES BY IMMUNOFERRITIN ELECTRONMICROSCOPY
}

\author{
F. G. RODGERS \\ Department of Microbiology and \\ Public Health Laboratory, University Hospital, Queen's Medical Centre, Nottingham \\ $N G 72 U H$
}

\begin{abstract}
SUMmary. Material from 18 lungs positive for Legionella pneumophila and 21 strains of legionellae grown on bacteriological media or in the yolk sac of fertile hen's eggs were examined by direct negative stain and immunoferritin electronmicroscopy. The 18 lung samples and all preparations of cultivated organisms showed the presence of bacteria with the typical morphology of $L$. pneumophila. By immunoferritin electronmicroscopy, with specific antisera, it was possible to serogroup the organisms. The immunoferritin method in reverse made it possible to detect and titrate antibody in sera from patients. Direct and immunoferritin electronmicroscopy were as sensitive as immunofluorescent antibody tests for detecting the antigens and antibodies of Legionnaires' disease. Additional advantages of the ultrastructural technique are discussed.
\end{abstract}

\section{INTRODUCTION}

Legionnaire's disease is the accepted name for an acute respiratory illness in man (Fraser et al., 1977), the causal agent of which is Legionella pneumophila (Brenner, Steigerwalt and McDade, 1979). The organisms are typically small gram-negative bacilli which have been isolated from post-mortem lung tissue on blood agar containing added iron and cysteine (Greaves, 1980), by intraperitoneal inoculation of guinea-pigs and yolk-sac inoculation of fertile hen's eggs.

Although organisms can be seen directly in suspensions or histological sections of post-mortem tissues by optical stains (Chandler, Hicklin and Blackmon, 1977; Rodgers, 1979a), specific immunofluorescent antibody staining (IFA) is most often needed for identification (Cherry et al., 1978). The better resolution and higher magnification afforded by negative-stain and thin-section electronmicroscopy show the organisms to have a distinctive morphology (Rodgers, Macrae and Lewis, 1978), are found intracellularly in lung macrophages (Rodgers, 1979b; Chandler et al., 1979), and possess flagella and pili (Rodgers et al., 1980; Chandler et al., 1980). The antigens of legionellae and the antibodies they induce in human sera have been detected with varying success by several means, including micro-agglutination, enzyme-linked immunosorbent assay (Farshy, Klein and Feeley, 1978), and counter immunoelectro- 
phoresis (Holliday, 1980). Despite this, IFA still remains the most widely used method (Cherry et al., 1978).

In a preliminary report on a limited number of specimens, immunoferritin electronmicroscopy (IFEM) was shown to be useful for identifying L. pneumophila serogroup-1 organisms in suspensions (Rodgers and Macrae, 1979). Similarly, organisms have been identified in thin sections of lung tissues (Rodgers, 1979b). This report amplifies the value of IFEM in the detection of legionellae by the examination of formalin-fixed post-mortem lung tissues, suspensions of infected yolk-sac membranes, and bacterial suspensions. A reverse procedure for detecting specific antibodies in sera from patients was also developed.

\section{MATERIALS AND METHODS}

Lung tissue and bacterial strains. Post-mortem lung tissue from 100 patients with pulmonary disease was preserved in formalin before examination for $L$. pneumophila by IFA and by negative-stain electronmicroscopy (EM). Including those found positive by IFA and EM, 34 were examined by IFEM.

Twenty-one strains of $L$. pneumophila comprising members of the six established serogroups were examined by direct EM and IFEM after cultivation on enriched blood agar (Greaves, 1980). These were: serogroup 1, strains Philadelphia 1 and 2, Pontiac 1, Cambridge 1, Washington 1, Nottingham N/P/1, N/M/2, N3, N/P/4, N5, N6, N7, N8, N9, Bloomington 1 and Corby 1; serogroup 2, strain Togus 1; serogroup 3, strain Bloomington 2; serogroup 4, strain Los Angeles 1; serogroup 5, strain Cambridge 2; and serogroup 6, strain Oxford 1. Strains Philadelphia 2 and Pontiac 1 were also examined as yolk-sac suspensions.

Direct electronmicroscopy. Small pieces of lung were ground up in Griffith's tubes in phosphate-buffered saline $p \mathrm{H} 7 \cdot 2$ (PBS-A); bacterial colonies and infected yolk sacs were similarly emulsified. From each turbid sample, a $20-\mu \mathrm{l}$ volume was added to a formvar-carboncoated EM grid and excess fluid was drained with filter paper. Grids were negatively stained by the addition of $1 \%(\mathrm{w} / \mathrm{v})$ phosphotungstic acid $p \mathrm{H} 6.5$ (Rodgers et al., 1980) and examined in either a Jeol $100 \mathrm{C}$ or AEI Corinth 500 electron microscope.

Immunoferritin electronmicroscopy. Teflon-coated slides used in IFA tests were cleaned in methanol and dried. Each well received $30 \mu \mathrm{l}$ of a 1 in 640 dilution in PBS-A of antiserum to strain Philadelphia 2 (serogroup 1) prepared in rabbits. Electronmicroscopy grids were made as described above but not stained. Each grid was placed specimen side down on a drop of antiserum and incubated for $30 \mathrm{~min}$ at $37^{\circ} \mathrm{C}$ in a moist atmosphere. Grids were removed and washed with $3 \mathrm{ml}$ of deionised water from a pasteur pipette, drained with filter paper and re-incubated in similar fashion on slides, the wells of which contained $30 \mu \mathrm{l}$ of goat anti-rabbit ferritin conjugated globulin (heavy and light chains) (Dynatech Laboratories, Billingshurst, West Sussex). The conjugated antiserum was diluted 1 in 200 in PBS-A containing Teepol HB6 $1 \%(\mathrm{v} / \mathrm{v})$ as a wetting agent, the use of which considerably reduced the non-specific adherence of labelled globulin to the support films of the EM grids. After washing as previously described, excess water was drained from the grids which were then examined, without further staining, at an initial magnification of 5000 to identify organisms and at a magnification of 25000 to locate ferritin granules. All specimens were also retested by IFEM with rabbit anti-legionella polyvalent (1-6) serum and, if positive, were further identified with serogroup 2,3,4 and 5 specific sera. Suspensions of Escherichia coli and Proteus mirabilis from bacteriological media were examined as controls. The method is illustrated in fig. 1 .

Serum samples from 12 patients with lobar pneumonia were examined for antibody by a reverse IFEM (RIFEM) method, five being negative and seven positive for antibodies to serogroup-1 L. pneumophila by IFA.

Reverse immunoferritin electronmicroscopy. Philadelphia-2 organisms, grown on enriched blood agar (Greaves, 1980) for 3 days in $5 \% \mathrm{CO}_{2}$ at $37^{\circ} \mathrm{C}$, were harvested and a thick suspension was prepared in PBS-A. To this was added formalin and a suspension of normal yolk-sac membrane in PBS-A to give final concentrations of $2 \%(\mathrm{v} / \mathrm{v})$ and $0 \cdot 5 \%(\mathrm{w} / \mathrm{v})$ respectively. EM 

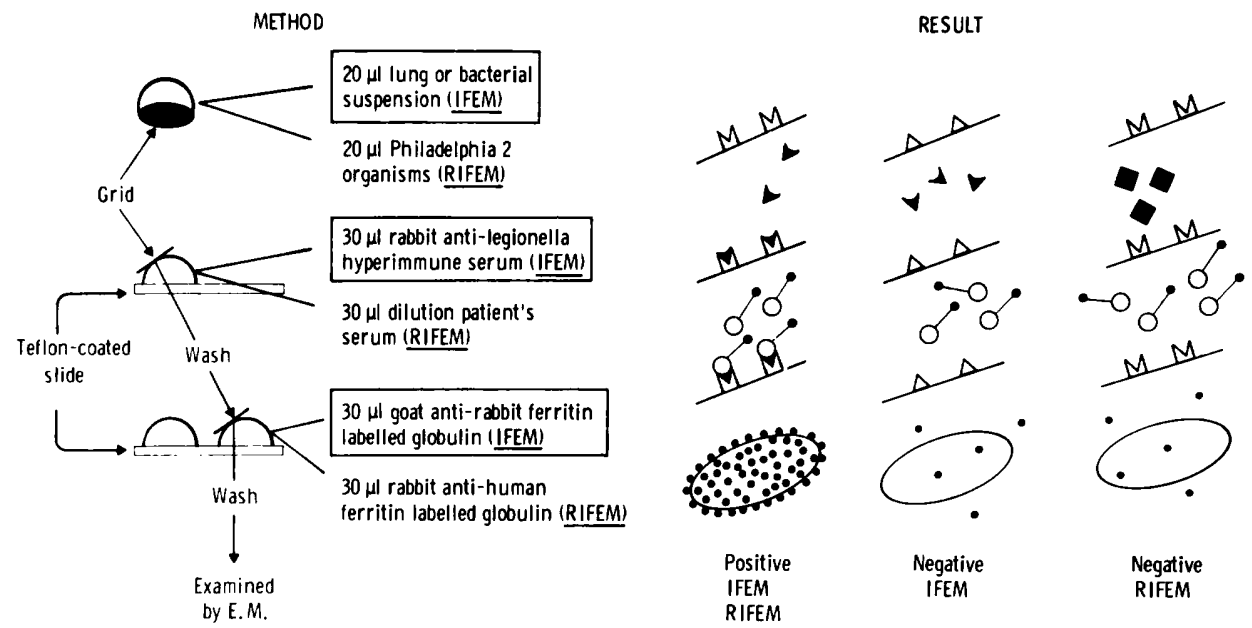
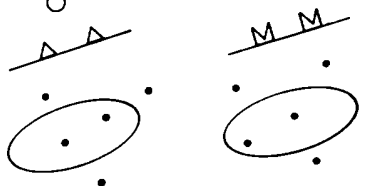

Negative

IFEM

Negative RIFEM

FIG. 1.-Method used in IFEM (boxed) and RIFEM (unboxed) test for detecting antigens and antibodies of L. pneumophila. $M=$ Legionella antigens; $\Lambda=$ non-legionella antigens; $\nabla=$ anti-legionella rabbit (IFEM) or patient (RIFEM) serum; $\diamond=$ non-legionella antibodies; $\rightarrow=$ ferritin-labelled anti-rabbit (IFEM) or anti-human (RIFEM) globulin.

grids with attached Philadelphia-2 organisms were incubated, as previously described, on $30-\mu$ l drops of diluted patient's serum, washed and re-incubated on $30 \mu \mathrm{l}$ of rabbit anti-human ferritin conjugated globulin prepared as in the IFEM test. The sera were coded, and screened at a dilution of 1 in 32 in PBS-A. Positive sera were titrated by doubling dilution in PBS-A on the Teflon-coated slides. The method is illustrated in fig. 1.

Immunofluorescent-antibody test. An indirect modification of the IFA technique was used to detect organisms and antibodies in the samples examined (Cherry et al., 1978).

\section{RESULTS}

In the IFEM and RIFEM tests the criterion for a positive result was the presence of ferritin granules specifically attached over the entire bacterial surfaces with little or no ferritin attached to the background support films (fig. 2).

Of the 100 formalinised lung specimens examined by direct EM, 18 contained organisms with legionella-like properties. The same specimens were positive for $L$. pneumophila by specific IFA staining - (17 serogroup 1 and one serogroup 5). Virus particles were not observed in any of these tissues. Of the 34 specimens tested by IFEM, 15 contained serogroup- 1 and one contained serogroup- 5 organisms. Two IFA-positive specimens, although positive by direct EM, contained too few organisms for detection by the IFEM test. Specimens positive for a given serogroup in the IFEM test were negative for the remaining serogroups. In nine specimens, only "coliformlike" organisms were detected by direct EM and in seven, bacteria were not seen. All 16 were negative by IFA and IFEM. These results are summarised in table I.

The 21 strains of L. pneumophila grown on bacteriological media and the two strains from the yolk sac of embryonated eggs were examined under code by direct EM and showed organisms characteristic of legionellae. All strains gave positive findings by IFA and by IFEM with polyvalent (1-6) rabbit antisera. With the 

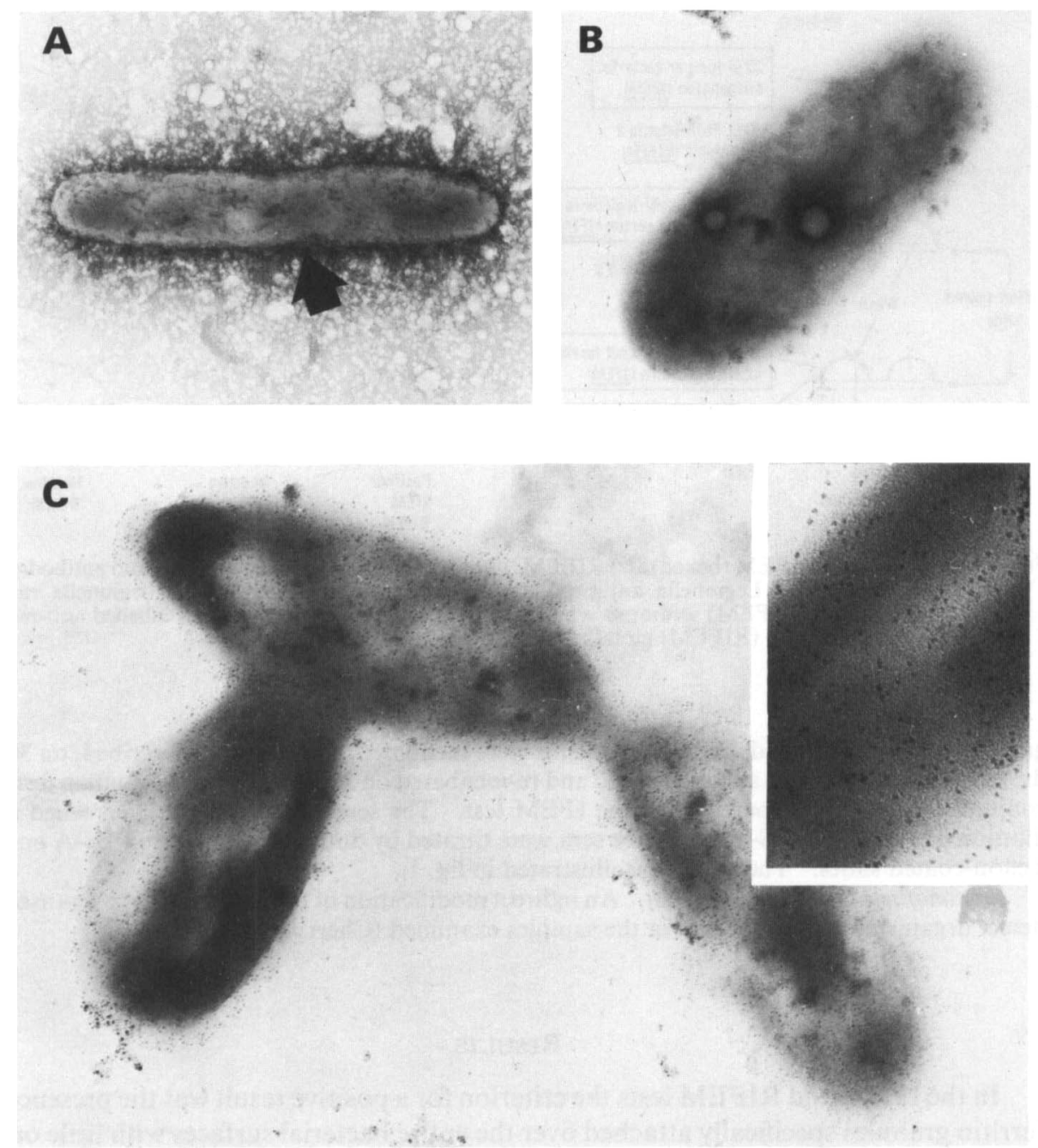

FIG. 2.-A, L. pneumophila organism from post-mortem lung tissue negatively stained with phosphotungstic acid $1 \%(\mathrm{w} / \mathrm{v}) \mathrm{pH} 6.5$. Note early division (arrow). EM. $\times 21600$. B, non-legionella organism in post-mortem lung tissue, negative by IFEM (unstained). EM. $\times 54000$. C, group of L. pneumophila serogroup- 1 organisms in lung tissue. Note ferritin grains attached specifically over the whole bacterial surfaces (unstained). EM. $\times 45000$. Inset shows higher magnification of bacterial cell wall with attached ferritin (unstained). EM. $\times 108000$.

serogroup-1 specific antisera, 16 were positive in both tests. Strains negative with serogroup- 1 antiserum but positive with the polyvalent serum corresponded to the five non-serogroup-1 strains, and four of these were further identified under code as one each of serogroups 2, 3, 4 and 5 with specific antisera. The fifth strain gave no reaction with monospecific antisera; however, serogroup-6 antiserum was not available. In addition, two strains of $E$. coli and one of $P$. mirabilis were negative in all tests (table II). 
TABLE I

Detection of Legionella pneumophila by direct electronmicroscopy, immunofluorescent antibody test and immunoferritin electronmicroscopy in post-mortem lung tissue

\begin{tabular}{|c|c|c|c|c|c|}
\hline \multirow{3}{*}{$\begin{array}{l}\text { Organisms seen by } \\
\text { direct EM }\end{array}$} & \multirow{3}{*}{$\begin{array}{c}\text { Number } \\
\text { of specimens }\end{array}$} & \multicolumn{4}{|c|}{$\begin{array}{l}\text { Number of specimens in which legionel- } \\
\text { lae of indicated serogroup were detected } \\
\text { by }\end{array}$} \\
\hline & & \multicolumn{2}{|c|}{ IFA } & \multicolumn{2}{|c|}{ IFEM } \\
\hline & & 1 & 5 & 1 & 5 \\
\hline $\begin{array}{l}\text { Legionella-like } \\
\text { Coliform-like only } \\
\text { None }\end{array}$ & $\begin{array}{c}18^{*} \\
9 \\
7\end{array}$ & $\begin{array}{r}17 \\
0 \\
0\end{array}$ & $\begin{array}{l}1 \\
0 \\
0\end{array}$ & $\begin{array}{c}15^{*} \\
0 \\
0\end{array}$ & $\begin{array}{l}1 \\
0 \\
0\end{array}$ \\
\hline
\end{tabular}

$\mathrm{EM}=$ electronmicroscopy, $\mathrm{IFA}=\mathrm{immunofluorescent}$ antibody, $\mathrm{IFEM}=\mathrm{im}$ munoferritin electronmicroscopy.

* Includes 5 with coliforms also present. These were distinguishable from legionella by IFEM.

\section{TABLE II}

Identification of cultivated Legionella pneumophila grown by direct electronmicroscopy, immunofluorescent antibody and immunoferritin electronmicroscopy

\begin{tabular}{|c|c|c|c|c|}
\hline \multirow{2}{*}{$\begin{array}{l}\text { Organisms seen by } \\
\text { direct EM }\end{array}$} & \multirow{2}{*}{$\begin{array}{l}\text { Number } \\
\text { of specimens }\end{array}$} & \multirow{2}{*}{$\begin{array}{l}\text { Antiserum } \\
\text { used }\end{array}$} & \multicolumn{2}{|c|}{$\begin{array}{c}\text { Number of specimens } \\
\text { positive by }\end{array}$} \\
\hline & & & IFA & IFEM \\
\hline Legionella-like* & 23 & $\begin{array}{l}\text { Polyvalent (1-6) } \\
\text { Serogroup 1 } \\
\text { Serogroup 2 } \\
\text { Serogroup 3 } \\
\text { Serogroup } 4 \\
\text { Serogroup 5 } \\
\text { Polyvalent (1-6) } \\
\text { Serogroup 1 }\end{array}$ & $\begin{array}{r}23 \\
18 \\
1 \\
1 \\
1 \\
1 \\
0 \\
0\end{array}$ & $\begin{array}{r}23 \\
18 \\
1 \\
1 \\
1 \\
1 \\
0 \\
0\end{array}$ \\
\hline
\end{tabular}

Abbreviations as in table I.

* 21 strains examined from enriched blood agar. Philadelphia 2 and Pontiac 1 additionally examined as yolk-sac suspensions.

+ Pure cultures of E. coli (2) and Proteus mirabilis (1).

Table III

Detection and titration of antibodies to Legionella pneumophila serogroup 1 in sera from patients by immunofluorescent antibody and reverse immunoferritin electronmicroscopy

\begin{tabular}{l|ccccccrccccc}
\hline \multirow{2}{*}{ Test } & \multicolumn{110}{|c}{ Titre of serum no. } \\
\cline { 2 - 12 } & 1 & 2 & 3 & 4 & 5 & 6 & 7 & 8 & 9 & 10 & 11 & 12 \\
\hline RIFEM & $<32$ & $<32$ & $<32$ & 256 & $<32$ & 32 & 128 & 512 & $<32$ & 256 & 128 & 1024 \\
IFA & $<16$ & $<16$ & $<16$ & 512 & $<16$ & 32 & 64 & 1024 & $<16$ & 128 & 512 & 1024 \\
\hline
\end{tabular}

RIFEM = reverse immunoferritin electronmicroscopy; IFA = immunofluorescent antibody. 
After decoding, tests on the 12 sera from patients showed good agreement between the IFA and RIFEM tests. The five sera negative for antibodies to L. pneumophila at the screen dilution by IFA (titre $<16$ ) were also negative by RIFEM, (titre $<32$ ). Of the remaining seven sera, six gave either identical titres, or endpoints within one doubling dilution. The seventh serum gave a result two dilution steps lower by RIFEM than by IFA (table III).

\section{Discussion}

Investigation of the nature of legionellosis, and in particular its diagnosis, the pattern of the infectious process and route of spread of bacteria from the environment to man, depend on the identification of legionella organisms. Culture techniques are not yet perfected. Determination of the incidence of disease requires the identification of specific antibodies. To these ends, the IFA test has proved most useful (Cherry et al., 1978). Detection methods best suited to screening large numbers of specimens, such as counter immunoelectrophoresis (Holliday, 1980), are up to six doubling-dilution steps less sensitive than IFA, and enzyme-linked and radioimmunoassay techniques have not yet proved adequate alternatives. EM has been suggested as a useful rapid method for the detection of $L$. pneumophila in post-mortem lung specimens (Rodgers, 1979b). However, this technique, like the Dieterle silver-impregnation method of Chandler et al. (1977), is not specific.

Ferritin antibody labelling has been used mainly in conjuction with thin-sectioning techniques to identify viral antigens (Andres, Hsu and Seegal, 1978), and more recently L. pneumophila in post-mortem lung tissue (Rodgers, 1979b). The elementary bodies of chlamydiae have been specifically identified in suspension by an immunoferritin technique (Ashley, Richmond and Caul, 1975).

The IFEM test, as described, was satisfactory for identifying $L$. pneumophila in suspensions of formalin-fixed post-mortem lung tissue and of strains from bacteriological culture media. An advantage of this technique was that direct EM could be used for visualisation of organisms with legionella-like properties, and these could then be subjected to IFEM with polyvalent followed by monospecific antisera. By these methods it was possible to serogroup and to distinguish the legionellae from contaminating coliform organisms even when the two were present in the same specimen. In addition, the RIFEM test detected antibodies to L. pneumophila of serogroup 1 in sera from patients with a sensitivity similar to that of IFA. The major disadvantages of the technique are that, like IFA, it is laborious, susceptible to subjective error, and not suited to automation.

The use of unfixed organisms in either the IFEM or the RIFEM test reduced the sensitivity in that ferritin granules adhered preferentially to extruded cytoplasmic contents of live bacteria with only small numbers attached to intact cells. Formalin fixation, however, effected an apparent even distribution of granules on the organisms. Whether the action of the fixative was to enhance the antigenicity of the bacterial surface or enabled the antisera to penetrate the cell wall and attach to cytoplasmic antigens was not clear, though the latter seems more probable.

The use of highly specific or monoclonal antibodies prepared to subcomponents of these organisms in conjuction with IFEM methods would prove useful for determining the antigenic structure of these related bacteria. The two techniques described add to 
the tests available for the laboratory diagnosis of legionellosis and extend the potential for additional research to establish the nature of this group of pathogens.

I thank the Center for Disease Control, Atlanta for the serogroup-1 antiserum, the Division of Microbiological Reagents and Quality Control, Colindale, for all other legionella antisera, $\mathrm{Mr}$ A. Laverick for the immunofluorescence work, Mrs Joan Casson for help in preparing the electron micrographs, and Dr A. D. Macrae for useful discussion.

\section{REFERENCES}

Andres, G. A., Hsu, K. C. And Seegal, B. C. 1978. Immunological techniques for the identification of antigens or antibodies by electron microscopy. In Handbook of experimental immunology, edited by D. M. Weir, 3rd ed., Blackwell Scientific Publications, Oxford, 37.1.

Ashley, C. R., Richmond, S. J. AND CAUL, E. O. (1975). Identification of the elementary bodies of Chlamydia trachomatis in the electron microscope by an indirect immunoferritin technique. J. Clin. Microbiol., 2, 327.

Brenner, D. J., Steigerwalt, A. G. and McDade, J. E. (1979). Classification of the Legionnaires' disease bacterium: Legionella pneumophila, genus novum, species nova of the family Legionellaceae familia nova. Ann. intern. Med., 90, 656.

Chandler, F. W., Cole, R. M., Hicklin, M. D., Blackman, J. A. and Callaway, C. S. (1979). Ultrastructure of the Legionnaires' disease bacterium. A study using transmission electron microscopy. Ann. intern. Med., 90, 642.

Chandler, F. W., Hicklin, M. D. and Blackmon, J. A. (1977). Demonstration of the agent of Legionnaires' disease in tissue. New Engl. J. Med., 297, 1218.

Chandler, F. W., Roth, I. L., Callaway, C. S., Bump, J. L., Thomason, B. M. and Weaver, R. E. (1980). Flagella on Legionnaires' disease bacteria-ultrastructural observations. Ann. intern. Med., 93, 711.

Cherry, W. B., Pittman, B., Harris, P. P., Hebert, G. A., Thomason, B. M., Thacker, L. and WEAVER, R. E. (1978). Detection of Legionnaires' disease bacteria by direct immunofluorescent staining. J. clin. Microbiol., 8, 329.

FARShy, C. E., Klein, G. C. AND Feeley, J. C. (1978). Detection of antibodies to Legionnaires' disease organism by micro-agglutination and micro-enzyme linked immunosorbent assay tests. J. clin. Microbiol., 7, 327.

Fraser, D. W., 11 others and the Field Investigation Team. (1977). Legionnaires' disease. Description of an epidemic of pneumonia. New Engl. J. Med., 297, 1189.

Greaves, P. W. (1980). New methods for the isolation of Legionella pneumophila. J. clin. Path., 33, 581.

Holliday, M. G. (1980). The diagnosis of Legionnaries' disease by counterimmunoelectrophoresis. J. clin. Path., 33, 1174.

RODGERS, F. G. (1979a). Staining of Legionella pneumophila. Lancet, i, 551.

Rodgers, F. G. (1979b). Ultrastructure of Legionella pneumophila. J. clin. Path., 32, 1195.

Rodgers, F. G., Greaves, P. W., Macrae, A. D. and Lewis, M. J. (1980). Electron microscopic evidence of flagella and pili on Legionella pneumophila. J.clin. Path., 33, 1184.

RodGers, F. G. AND MACRAE, A. D. (1979). Immunoferritin electron microscopy in legionellosis. Lancet, 1, 786.

RodGers, F. G., MaCrae, A. D. AND LewIS, M. J. (1978). Electron microscopy of the organism of Legionnaries' disease. Nature, Lond., 272, 825. 